\title{
KEHILANGAN AIR DAN PENAMBAHAN PADATAN YANG TERJADI SELAMA PROSES DEHIDRASI OSMOTIK BUAH NAGA
}

\section{WATER LOSS AND SOLID GAIN THAT OCCURRED DURING OSMOTIC DEHYDRATION PROCESS OF DRAGON FRUIT}

\author{
Spetriani $^{1^{*}}$, Siti Fathurahmi ${ }^{1}$, If' all ${ }^{1}$ \\ ${ }^{1}$ Program Studi Teknologi Hasil Pertanian, Fakultas Pertanian, Universitas Alkhairaat, \\ Jl. Diponegoro, Fakultas Pertanian Universitas Alkhairaat, Palu 94221, Indonesia
}

\begin{abstract}
ABSTRAK
Dehidrasi osmotik merupakan metode yang dapat dilakukan pada perlakuan awal pengeringan dengan cara merendam bahan ke dalam larutan hipertonik. Tujuan dari penelitian ini adalah untuk mengkaji pengaruh konsentrasi dan suhu larutan osmotik terhadap tingkat kehilangan air (WL) dan penambahan padatan (SG) pada potongan buah naga selama proses dehidrasi osmotik berlangsung. Potongan buah naga direndam ke dalam larutan osmotik dengan level konsentrasi dan suhu larutan yang berbeda (30 ${ }^{\circ}$ Briks, $50{ }^{\circ}$ Briks, dan $70{ }^{\circ}$ Briks, serta $30{ }^{\circ} \mathrm{C}, 40{ }^{\circ} \mathrm{C}$ dan $50{ }^{\circ} \mathrm{C}$ ). Nilai WL untuk konsentrasi larutan 30 ${ }^{\circ}$ Briks bervariasi mulai dari $17,42 \%$ hingga $25,26 \%$, untuk konsentrasi $50{ }^{\circ}$ Briks adalah 32,84\% hingga 50,38 \%, dan untuk konsentrasi $70{ }^{\circ}$ Briks adalah 39,89\% hingga 57,99\%. Dengan demikian, perubahan tingkat WL dipengaruhi oleh konsentrasi dan suhu larutan, dimana semakin tinggi konsentrasi dan suhu larutan, WL bahan semakin besar. Sedangkan untuk SG pada bahan diperoleh nilai yang berkisar antara 2,092\% - 10,010\%. Berdasarkan perhitungan model Azuara nilai WL berkisar antara 21,551\% - 75, $187 \%$ dan 3,899\% - 17,575\% untuk nilai SG. Koefisien determinasi untuk perhitungan model Azuara sebesar 0,938 - 0,992, dengan demikian model Azuara dapat dikatakan layak untuk pemodelan nilai WL dan SG pada dehidrasi osmotik buah naga.
\end{abstract}

Kata kunci: dehidrasi osmotik; buah naga; kehilangan air; penambahan padatan

\section{ABSTRACT}

Osmotic dehydration is a method that can be used in the pretreatment of drying by immersing the material in a hypertonic solution. The purpose of this study was to examine the effect of concentration and temperature of the osmotic solution on water loss and solid gain to dragon fruit pieces during the osmotic dehydration process. Dragon fruit slices were immersed in osmotic solution with different concentration and temperature solution $\left(30^{\circ} \mathrm{Brix}, 50^{\circ} \mathrm{Brix}\right.$, and $70^{\circ} \mathrm{Brix}$, as well as $30^{\circ} \mathrm{C}, 40^{\circ} \mathrm{C}$, and 50 ${ }^{\circ} \mathrm{C}$ ). The WL value for the concentration of 30 oBrix solution varies from $17.42 \%$ to $25.26 \%$, for a 50 oBrix concentration is $32.84 \%$ to $50.38 \%$, and for a 70 oBrix concentration is $39.89 \%$ to $57.99 \%$. Thus, changes in the level of WL, concentration and temperature of the solution, where the higher the concentration and temperature of the solution, the greater the WL of the material. Meanwhile, for SG on materials, values ranged from 2.092\% -10.010\%. Based on the calculation of the Azuara model, the WL values ranged from $21.551 \%-75,187 \%$ and $3.899 \%-17.575 \%$ for the SG value. The coefficient of determination for the calculation of the Azuara model is 0.938 - 0.992, thus the Azuara model can be said to be feasible for modeling the WL and SG values on osmotic dehydration of dragon fruit.

Keywords: osmotic dehydration; dragon fruit; water loss; solid gain

\section{Pendahuluan}

${ }^{*}$ Penulis Korespondensi.

E-mail: spetriani8@gmail.com

Telp: +62-852-1400-0429

Hasil pertanian khususnya komoditas buah dan sayur adalah komoditas yang mudah rusak. Penyebab utama kerusakan tersebut adalah kadar air yang terkandung di dalamnya cukup tinggi 
(Yadav and Singh 2014). Berbagai metode dilakukan untuk mempertahankan mutu buah dan sayur selama mungkin. Salah satu metode pencegahan kerusakan buah dan sayur adalah dengan dehidrasi osmotik. Proses dehidrasi osmotik diterapkan secara luas untuk mendapatkan pangan semi basah yang berkualitas tinggi (Derossi et al. 2008) serta digunakan sebagai pre-treatment buah tropis dengan tujuan akhir mendapatkan produk buah kering yang berkualitas (Lombard et al. 2008).

Dehidrasi osmotik dilakukan dengan cara merendam bahan pangan ke dalam larutan hipertonik sebagai langkah awal untuk pengeringan selanjutnya. Dehidrasi osmotik dapat digunakan untuk perlakuan awal pengeringan yang dapat menurunkan kadar air bahan hingga $50 \%$ dari kadar air awal (Karathanos, Kostaropoulos, and Saravacos 1995). Larutan hipertonik yang biasa digunakan pada proses osmotik untuk komoditas buah adalah larutan gula dengan konsentrasi tertentu. Selama proses dehidrasi osmotik berjalan, bahan pangan akan mengalami kehilangan air (water loss) dan penambahan padatan (solid gain) akibat keluarnya air dari jaringan bahan ke larutan osmotik dan aliran padatan terlarut dari osmotik ke dalam jaringan bahan (Khan et al. 2008).

Peningkatan suhu dan konsentrasi medium osmotik menyebabkan water loss (WL) dan solid gain (SG). Penurunan rasio sampel terhadap larutan menghindari pengenceran media yang signifikan dengan menghilangkan air dan selanjutnya menurunkan gaya penggerak osmotik selama proses (Ispir and Toğrul 2009). Hal ini sejalan dengan dehidrasi osmotik yang dilakukan oleh Lombard et al. (2008) pada potongan buah nanas menyatakan bahwa kehilangan air dan penambahan padatan meningkat seiring dengan peningkatan suhu dan konsentrasi larutan osmotik yang digunakan. penelitian lain yang dilakukan oleh El-Aouar et al. (2006) menunjukkan bahwa nilai yang diperoleh untuk water loss dan solid gain untuk dehidrasi dalam larutan sukrosa lebih tinggi dibandingkan dengan dehidrasi dalam larutan sirup jagung.

Tujuan penelitian ini adalah untuk mengkaji pengaruh konsentrasi dan suhu larutan osmotik terhadap tingkat kehilangan air dan penambahan padatan pada potongan buah naga selama proses dehidrasi osmotik berlangsung.

\section{Metode Penelitian}

Penelitian dilaksanakan pada Maret 2015 di laboratorium Teknik Pangan dan Pascapanen Fakultas Teknologi Pertanian, UGM, Yogyakarta. Bahan utama yang digunakan pada penelitian adalah buah naga dan larutan osmotik yang dibuat dari campuran gula dan aquades. Peralatan yang digunakan selama penelitian adalah waterbath (Neslab instrument, Inc. Newington, NH 03801 U.S.A) drying oven (Memmert, Type UM 400), timbangan analitik (shimadzu, Type AUW220), termokopel, penjepit cawan, tray, desikator, gelas ukur dan pinset.

\section{Analisa Data}

Data hasil penelitian dianalisa menggunakan Rancangan faktorial yang terdiri dari dua faktor yaitu konsentrasi larutan osmotik dan suhu larutan osmotik. Masing-masing faktor terdiri dari 3 taraf yaitu taraf konsentrasi larutan osmotik $30{ }^{\circ} \mathrm{Briks}, 50{ }^{\circ} \mathrm{Briks}$, dan $70{ }^{\circ} \mathrm{Briks}$ serta taraf suhu larutan osmotik yaitu $30{ }^{\circ} \mathrm{C}, 40{ }^{\circ} \mathrm{C}$, dan $50{ }^{\circ} \mathrm{C}$. Sehingga perlakuan berjumlah 9 dengan kombinasi sebagaimana yang terdapat dalam Tabel 1.

Tabel 1. Jenis perlakuan, kombinasi dan notasi perlakuan

\begin{tabular}{llll}
\multirow{2}{*}{$\begin{array}{l}\text { Konsentrasi } \\
\text { Larutan (B) }\end{array}$} & \multicolumn{3}{c}{ Suhu Larutan (T) } \\
\cline { 2 - 4 } & & & \\
\cline { 2 - 4 } & $\mathbf{3 0}^{\circ} \mathbf{C}$ & $\mathbf{4 0}^{\circ} \mathbf{C}$ & $\mathbf{5 0}^{\circ} \mathbf{C}$ \\
\hline $30^{\circ}$ Briks & B1T1 & B1T2 & B1T3 \\
$50^{\circ}$ Briks & B2T1 & B2T2 & B2T3 \\
$70{ }^{\circ}$ Briks & B3T1 & B3T2 & B3T3 \\
\hline
\end{tabular}

Kehilangan air atau water loss (water loss/100 g sampel) dan solid gain (solute gain/100 g sampel) selama dehidrasi osmotik dihitung menggunakan persamaan berikut (Shi et al. 1995) :

$$
\begin{aligned}
\mathrm{WL} & =\frac{M_{0} X_{w 0}-M_{t} X_{w t}}{M_{0}} \\
\mathrm{SG} & =\frac{M_{t} X_{s t}-M_{0} X_{s 0}}{M_{0}}
\end{aligned}
$$

Dimana $\mathrm{M}_{0}$ dan $\mathrm{M}_{\mathrm{t}}$ adalah massa awal dan akhir sampel (g) $X_{w 0}$ dan $X_{w t}$ adalah kadar air awal dan akhir sampel (g water/100 g) dan $\mathrm{X}_{\mathrm{s} 0}$ dan $X_{\text {st }}$ adalah total padatan terlarut awal dan akhir sampel (g solid/100 g). 
Azuara et al. (1992) menghitung WL dan SG melalui persamaan dengan dua parameter yang diperoleh dari kesetimbangan massa.

$$
W L_{t}=\frac{\beta_{1} t\left(W L_{\infty}\right)}{1+\beta_{1} t}
$$

WL $\infty$ adalah water loss pada waktu tak hingga atau water loss pada saat kesetimbangan sedangkan $\beta_{1}$ adalah konstanta yang berkaitan dengan laju difusi. Jika dilinerkan maka persamaan tersebut menjadi

$$
\frac{t}{W L_{t}}=\frac{1}{W L_{\infty}}(t)+\frac{1}{\beta_{1} W L_{\infty}}
$$

Dengan memplotkan $\frac{t}{W L_{t}}$ versus t maka nilai $\mathrm{WL} \infty$ dan $\beta_{1}$ dapat dihitung dari slope dan intersep persamaan garis liniernya. Solid gain dapat dihitung dengan cara yang sama, sehingga dapat ditulis persamaan

$$
\begin{gathered}
S G_{t}=\frac{\beta_{2} t\left(S G_{\infty}\right)}{1+\beta_{2} t} \\
\frac{t}{S G_{t}}=\frac{1}{S G_{\infty}}(t)+\frac{1}{\beta_{2} S G_{\infty}}
\end{gathered}
$$

Dimana SGt $=$ solid gain pada waktu $\mathrm{t}, \mathrm{SG} \infty$ $=$ solid gain pada waktu tak hingga atau kesetimbangan dan $\beta_{2}=$ konstanta yang berkaitan dengan laju difusi solid.

Perhitungan rasio kinerja proses dehidrasi osmotik dapat dilakukan dengan membandingkan jumlah air yang keluar dari sampel terhadap padatan terlarut yang masuk dalam sampel

$$
P R=\frac{W L}{S G}
$$

\section{Hasil dan Pembahasan}

Nilai water loss menunjukkan tingkat kehilangan air pada bahan selama proses dehidrasi osmotik berlangsung. Pada Gambar 1 menunjukkan bahwa peningkatan WL dipengaruhi oleh tingkat konsentrasi larutan yang digunakan. Tingkat kehilangan air di menit ke480 pada konsentrasi larutan $30{ }^{\circ}$ Briks berkisar antara $17,42 \%$ - 25,26\%, pada konsentrasi 50 ${ }^{\circ}$ Briks berkisar antara 32,84 \% - 50,38 \%, sedangkan pada konsentrasi $70{ }^{\circ}$ Briks nilai WL antara $39,89 \%-57,99 \%$. Semakin tinggi konsentrasi larutan osmotik semakin tinggi pula tingkat kehilangan air yang dialami oleh bahan. Menurut Lilis Sucahyo (2014) peningkatan nilai WL dapat disebabkan karena kondisi konsentrasi yang lebih tinggi terjadi perbedaan tekanan osmotik yang lebih besar antara larutan gula dengan air yang terdapat di dalam irisan bahan. Perbedaan tersebut menjadi driving force yang menyebabkan massa air pada bahan mengalir keluar membran dan jaringan bahan menuju media larutan.

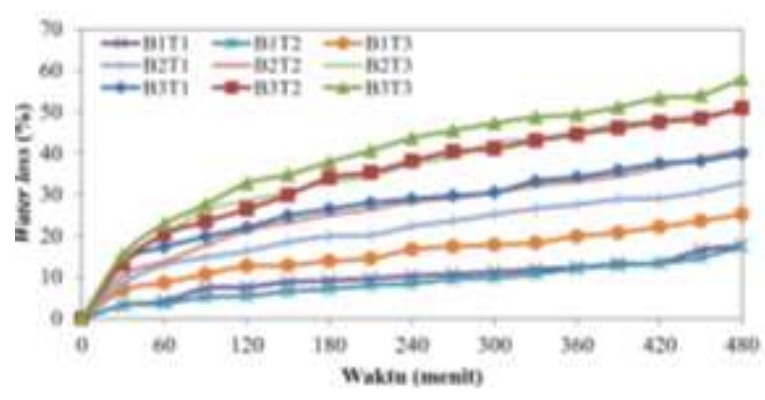

Gambar 1. Perubahan nilai WL selama proses dehidrasi osmotik

Peningkatan nilai WL juga terjadi karena dipengaruhi oleh suhu larutan osmotik. Semakin tinggi suhu larutan osmotik semakin tinggi pula tingkat kehilangan air yang terjadi. Pada konsentrasi yang sama, untuk suhu yang berbeda menunjukkan nilai WL yang berbeda pula. Seperti pada konsentrasi $30{ }^{\circ}$ Briks, nilai WL untuk suhu $30{ }^{\circ} \mathrm{C}$ adalah sebesar $17,614 \%$, sedangkan untuk suhu $50{ }^{\circ} \mathrm{C}$ sebesar $25,267 \%$.

Secara statistik, perbedaan tingkat konsentrasi dan suhu larutan memberikan pengaruh terhadap nilai WL bahan setelah proses dehidrasi osmotik. Hal ini dibuktikan oleh nilai signifikansi untuk variasi konsentrasi, variasi suhu dan interaksi antara keduanya kurang dari 0,05 berdasarkan hasil perhitungan anova dua arah. Analisis dilanjutkan dengan uji DMRT untuk mengetahui perbedaan pengaruh masingmasing variasi perlakuan yang diujikan. Hasil uji DMRT untuk WL terdapat pada Tabel 2. Dari hasil uji DMRT diperoleh kesimpulan bahwa terdapat beda nyata antara masing-masing taraf perlakuan, baik pada konsentrasi maupun suhu larutan. Antara ketiga variasi konsentrasi dan suhu yang digunakan dinyatakan berbeda nyata satu sama lain. Hal ini ditunjukkan pada posisi hasil hitung berada pada kolom subset yang berbeda.

Nilai kehilangan air bahan terjadi dengan cepat pada awal proses dehidrasi osmotik dan terjadi penurunan laju kehilangan air pada menit - menit terakhir proses osmotik. Hal ini terjadi karena air terikat yang terkandung pada bahan cukup sulit untuk dikeluarkan. Bentuk garis pada grafik lama-kelamaan akan mencapai konstan 
hingga bahan mencapai tingkat WL $\infty$ (Water Loss untuk waktu tak hingga atau kondisi kesetimbangan)

Tabel 2. Hasil uji DMRT pengaruh perlakuan terhadap WL

\begin{tabular}{lcccc}
\hline & & \multicolumn{3}{c}{ Subset } \\
\cline { 3 - 5 } Variasi perlakuan & & \multicolumn{3}{c}{3} \\
\hline Briks & $30^{\circ} \mathrm{Briks}$ & 21,997 & & \\
& $50^{\circ} \mathrm{Briks}$ & & 41,763 & \\
& $70^{\circ} \mathrm{Briks}$ & & & 51,336 \\
Suhu & $30^{\circ} \mathrm{C}$ & 31,043 & & \\
& $40^{\circ} \mathrm{C}$ & & 37,086 & \\
& $50^{\circ} \mathrm{C}$ & & & 46,969 \\
\hline
\end{tabular}

Perhitungan nilai $\mathrm{WL} \infty$ dan $\mathrm{SG} \infty$ serta konstanta yang menyertainya yang mengikuti model Azuara dapat dilihat pada Tabel 3.

Tabel 3. Nilai WL dan SG serta konstanta model Azuara

\begin{tabular}{cccrl}
\hline Perlakuan & WL $\infty$ & \multicolumn{1}{c}{$\boldsymbol{\beta}_{1}$} & \multicolumn{1}{l}{ SG $\infty$} & \multicolumn{1}{l}{$\boldsymbol{\beta}_{2}$} \\
\hline B1T1 & 21,551 & 0,004 & 6,614 & 0,013 \\
B1T2 & 26,666 & 0,002 & 3,899 & 0,004 \\
B1T3 & 32,573 & 0,004 & 17,575 & 0,001 \\
B2T1 & 40,65 & 0,005 & 10,537 & 0,006 \\
B2T2 & 50,761 & 0,005 & 6,882 & 0,012 \\
B2T3 & 64,102 & 0,006 & 7,698 & 0,007 \\
B3T1 & 47,169 & 0,006 & 7,386 & 0,007 \\
B3T2 & 66,225 & 0,005 & 7,369 & 0,008 \\
B3T3 & 75,187 & 0,005 & 11,351 & 0,007 \\
\hline
\end{tabular}

Nilai WL $\infty$ dan $\beta_{1}$ yang diperoleh dari perhitungan model Azuara dapat digunakan untuk memprediksi perubahan WL selama proses dehidrasi osmotik berlangsung. Pada Gambar 2, Gambar 3, dan Gambar 4 disajikan grafik yang menunjukkan perbandingan nilai WL antara observasi dengan prediksi model Azuara selama proses dehidrasi osmotik. Gambar grafik perbandingan tersebut menunjukkan bahwa WL hasil pengukuran mendekati sama dengan WL hasil perhitungan model walaupun tidak semua titik pengukuran berada tepat pada garis perhitungan. Nilai koefisien determinasi $\left(\mathrm{R}^{2}\right)$ perhitungan WL untuk setiap perlakuan berdasarkan model Azuara berkisar antara 0,9380,992 .

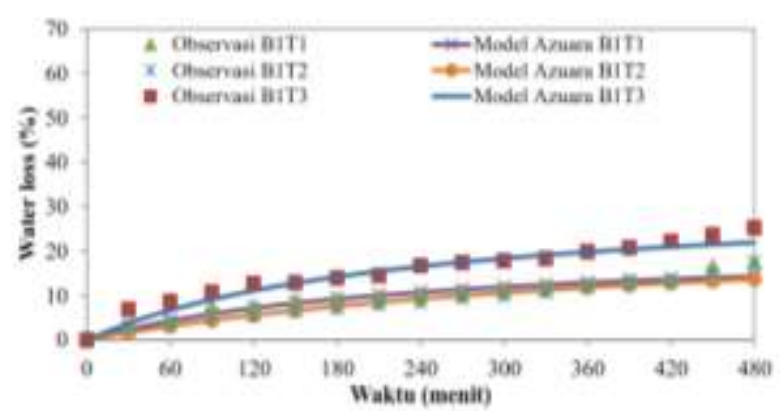

Gambar 2. Nilai WL observasi dan model Azuara (konsentrasi $30^{\circ} \mathrm{Briks}$ )

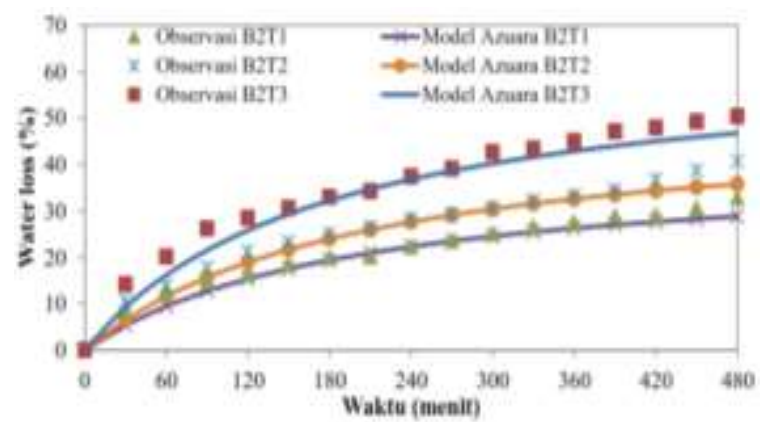

Gambar 3. Nilai WL observasi dan model Azuara (konsentrasi $50{ }^{\circ} \mathrm{Briks}$ )

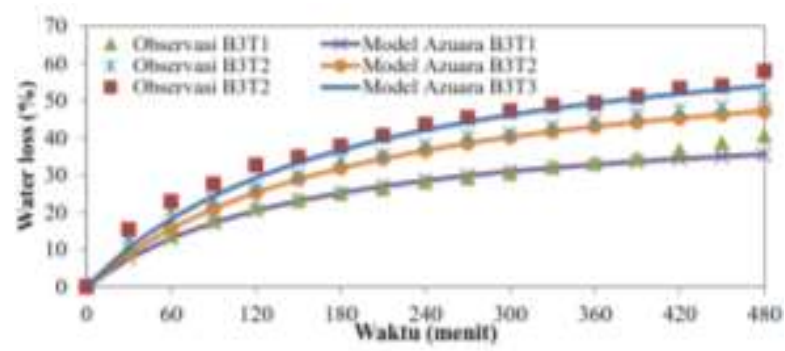

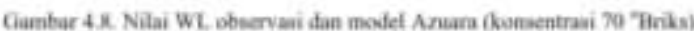

Gambar 4. Nilai WL observasi dan model Azuara (konsentrasi $70{ }^{\circ} \mathrm{Briks}$ )

Terdapat dua aliran massa yang berlawanan arah dan terjadi secara simultan selama proses dehidrasi osmotik. Aliran massa air yang berpindah dari bahan keluar menuju larutan osmotik dan massa padatan terlarut yang terkandung dalam larutan ke dalam jaringan bahan. Banyaknya massa air yang pindah ditunjukkan dengan nilai WL sedangkan banyaknya massa padatan terlarut yang masuk ke dalam bahan selama proses dehidrasi osmotik berlangsung ditunjukkan dengan nilai SG. Namun, peningkatan nilai WL tidak selalu diikuti dengan peningkatan nilai Solid Gain (SG). Nilai SG yang tinggi mengindikasikan bahwa jumlah padatan terlarut yang masuk ke bahan semakin banyak. Besarnya nilai SG pada dehidrasi osmotik diupayakan tidak terlalu tinggi karena 
dapat mempengaruhi rasa dari bahan terutama tingkat kemanisan bahan tersebut. Nilai SG selama proses dehidrasi osmotik ditunjukkan pada Gambar.

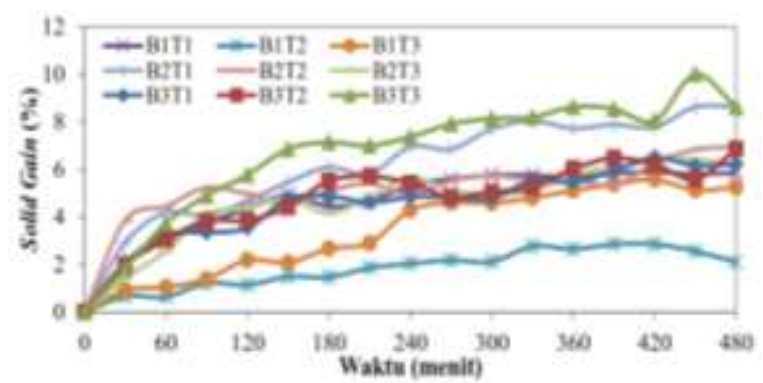

Gambar 5. Perubahan nilai SG bahan selama proses dehidrasi osmotik

Nilai $\mathrm{SG} \infty$ dan $\beta_{2}$ yang tercantum dalam Tabel 3 digunakan untuk memprediksi SG selama proses dehidrasi osmotik berdasarkan model Azuara. Perbandingan nilai SG berdasarkan observasi dan hasil hitung model Azuara dapat dilihat pada Gambar 6, Gambar 7 hingga Gambar 8. Nilai R2 untuk perhitungan SG model Azuara berkisar antara 0,819 hingga 0,986 .

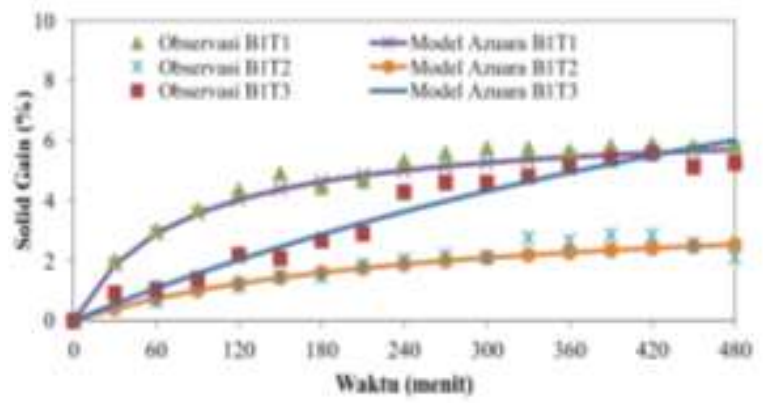

Gambar 6. Nilai SG observasi dan model Azuara (konsentrasi $30{ }^{\circ} \mathrm{Briks}$ )

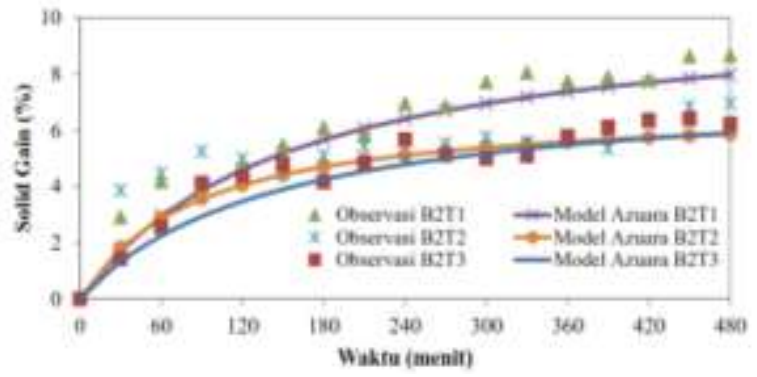

Gambar 7. Nilai SG observasi dan model Azuara (konsentrasi $50{ }^{\circ} \mathrm{Briks}$ )

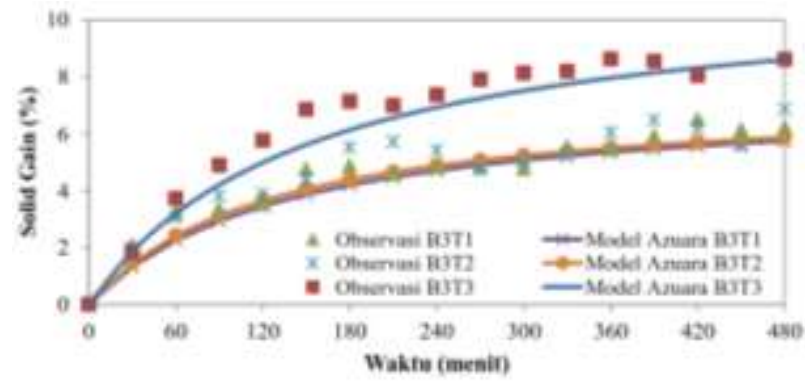

Gambar 8. Nilai SG observasi dan model Azuara (konsentrasi $70{ }^{\circ}$ Briks)

\section{Performance Ratio}

Performance Ratio (PR) adalah nilai yang menunjukkan besarnya kinerja dari proses dehidrasi osmotik. Hasil dari perbandingan antara nilai WL dan SG digunakan untuk menghitung besarnya PR. Nilai WL yang tinggi diikuti oleh nilai SG yang rendah dapat meningkatkan nilai PR pada proses dehidrasi osmotik. Pada Tabel 4 disajikan besaran nilai $\mathrm{PR}$ berdasarkan hasil observasi dan perhitungan model Azuara untuk masing-masing perlakuan. Nilai PR terbesar menurut hasil observasi terjadi pada perlakuan B3T2 (konsentrasi larutan $70{ }^{\circ}$ Briks dan suhu 50 $\left.{ }^{\circ} \mathrm{C}\right)$. Pada perlakuan dengan konsentrasi $70{ }^{\circ}$ Briks memiliki nilai PR yang hampir sama untuk setiap variasi perbedaan suhu konsentrasinya baik secara observasi maupun hasil perhitungan model Azuara.

Tabel 4. Nilai PR berdasarkan observasi dan perhitungan model Azuara

\begin{tabular}{lcccccc}
\hline Perlakuaa & \multicolumn{3}{c}{ Observasi } & \multicolumn{3}{c}{ Model Azuara } \\
\cline { 2 - 7 } & WL & SG & PR & WL & SG & PR \\
\hline BIT1 & 17,614 & 5,877 & 2,997 & 14,325 & 5,703 & 2,512 \\
BIT2 & 17,421 & 2,092 & 8,327 & 13,716 & 2,535 & 5,410 \\
BIT3 & 25,267 & 5,250 & 4,813 & 21,936 & 6,020 & 3,644 \\
B2T1 & 32,839 & 8,658 & 3,793 & 28,810 & 7,965 & 3,617 \\
B2T2 & 40,681 & 6,958 & 5,847 & 35,779 & 5,861 & 6,105 \\
B2T3 & 50,380 & 6,215 & 8,107 & 46,745 & 5,900 & 7,923 \\
B3T1 & 39,893 & 6,232 & 6,401 & 35,559 & 5,757 & 6,176 \\
B3T2 & 50,955 & 6,864 & 7,424 & 47,184 & 5,878 & 8,027 \\
B3T3 & 57,988 & 8,619 & 6,728 & 53,976 & 8,611 & 6,268 \\
\hline
\end{tabular}

\section{Kesimpulan}

Perbedaan konsentrasi larutan dan suhu larutan memberikan pengaruh terhadap perubahan WL. Semakin tinggi konsentrasi larutan semakin besar perubahan WL yang terjadi pada bahan. Begitupula yang terjadi pada suhu larutan, semakin tinggi suhu larutan semakin besar perubahan WL dari bahan. Sedangkan pada SG, perbedaan konsentrasi dan suhu larutan tidak 
memberikan pengaruh yang nyata terhadap SG pada bahan.

\section{Daftar Pustaka}

Azuara E, Cortes R, Garcia HS, Beristain CI. 1992. Kinetic model for osmotic dehydration and its relationship with fick's second law. Int J Food Sci Tech. 27:409418.

Derossi, A., T. De Pilli, C. Severini, and M. J. McCarthy. 2008. "Mass Transfer during Osmotic Dehydration of Apples." Journal of Food Engineering. doi: 10.1016/j.jfoodeng.2007.11.007.

El-Aouar, Ânoar Abbas, Patrícia Moreira Azoubel, José Lucena Barbosa, and Fernanda Elizabeth Xidieh Murr. 2006. "Influence of the Osmotic Agent on the Osmotic Dehydration of Papaya (Carica Papaya L.)." Journal of Food Engineering. doi: 10.1016/j.jfoodeng.2005.04.016.

Ispir, Ayşe, and Inci Türk Toğrul. 2009. "Osmotic Dehydration of Apricot: Kinetics and the Effect of Process Parameters." Chemical Engineering Research and Design. doi: 10.1016/j.cherd.2008.07.011.
Karathanos, V. T., A. E. Kostaropoulos, and G. D. Saravacos. 1995. "Air-Drying Kinetics of Osmotically Dehydrated Fruits." Drying Technology. doi: 10.1080/07373939508917036.

Khan, M. A. M., L. Ahrné, J. C. Oliveira, and F. A. R. Oliveira. 2008. "Prediction of Water and Soluble Solids Concentration during Osmotic Dehydration of Mango." Food and Bioproducts Processing. doi: 10.1016/j.fbp.2007.10.012.

Lilis Sucahyo, Leopold O. Nelwan, Dyah Wulandani, Hiroshi Nabetani TIP. 2014. "Rekonsentrasi Larutan Gula Pada Proses Dehidrasi Osmotik Irisan Mangga (Mangifera Indica L.) Dengan Teknik Distilasi Membran DCMD." Jurnal Teknologi Industri Pertanian.

Lombard, G. E., J. C. Oliveira, P. Fito, and A. Andrés. 2008. "Osmotic Dehydration of Pineapple as a Pre-Treatment for Further Drying." Journal of Food Engineering. doi: 10.1016/j.jfoodeng.2007.07.009.

Yadav, Ashok Kumar, and Satya Vir Singh. 2014. "Osmotic Dehydration of Fruits and Vegetables: A Review." Journal of Food Science and Technology. 